\title{
REPORT FROM THE 1ST NATIONAL POLISH SCIENTIFIC CONFERENCE IN THE CYCLE “DIAGNOSIS IN PSYCHOLOGICAL PRACTICE" ENTITLED “MODERN DIAGNOSTIC PRACTICE - ACHIEVEMENTS AND CHALLENGES", WARSAW (POLAND), 16-17 MARCH 2017
}

\author{
Marta GÓRSKA \\ Military Institute of Aviation Medicine, Department of Aviation Psychology, Warsaw, Poland
}

Source of support: Own sources

Author's address: M. Górska, Military Institute of Aviation Medicine, Department of Aviation Psychology, Krasińskiego 54/56 Street, 01-755 Warsaw, Poland, e-mail: mgorska@wiml.waw.pl

On 16-17 March 2017, in Warsaw, the 1st National Polish Scientific Conference in the cycle "Diagnosis in psychological practice" entitled "Modern diagnostic practice - achievements and challenges" took place under the auspices of the National Diagnostics Section of the Polish Psychological Association, PTP Test Labs and Psyche Bookshop. Among its participants were psychologists from the Department of Aviation Psychology, Piotr Zieliński, Ph.D., and Marta Górska, MSc. The psychologists from the Department of Psychology of the Military Institute of Aviation Medicine exchanged experiences on the current achievements of psychological diagnostics (research results, standards, diagnostic strategies, tools), and shared their problems related to psychological diagnosis.
Dr Piotr Zieliński took up a highly specialized topic on the accuracy of psychological tests, pointing to other alternative methods that are often more precise than those that are widely known. Dr Zieliński pointed out that modern psychometry has a lot to offer to both the creators and users of psychological tests. Today, the development of computer programs makes it easy to apply even very complex models within the IRT. Within the classical test theory, new methods of estimating reliability are becoming more popular as a reasonable alternative to the increasingly common Cronbach alpha coefficient. Compared to older "classical" methods, all this results in much better coping with the problem of measurement precision. The presentation was a personal reflection of the author, which provoked the audience to a lively, substantive discussion.

Full-text PDF: http://www.pjambp.com • Copyright @ 2016 Polish Aviation Medicine Society, ul. Krasińskiego 54/56, 01-755 Warsaw, license WIML • Indexation: Index Copernicus, Polish Ministry of Science and Higher Education 
Marta Górska, MSc., opened a session on Clinical Diagnosis by discussing the topic of kinesiophobia - a fear of movement; at the same time, she presented her own tool to measure this phenomenon. Marta Górska's tool was created as a result of two years of psychotherapeutic work with patients after extensive spine and knee surgery. Many of them were referred by physicians or physiotherapists, because the degree of muscle tension and fear of the onset of pain was so strong that it hindered further treatments. The measurement of the level of kinesiophobia aims to show the patient's ways of thinking about pain experiences as well as visualize the effects of this type of interpretation in the patient's behavior. Perceiving painful sensations as a threat can slow down or even halt the recovery process of postoperative patients, which can have important consequences for further functioning. One of them is entering the state of chronic pain. The subject matter raised by Marta Górska is a unique yet very important area, which finds its place in both the psychological and medical approach.

The conference "Diagnosis in psychological practice" entitled "Modern diagnostic practice - achievements and challenges" is an event that is organized cyclically and undertakes multi-facet- ed and key issues in psychological diagnosis. The conference is intended for psychologists who face the challenges of diagnostic practice on a daily basis but also for scientists interested in dialog with practices and seeking ways to implement today's scientific knowledge into psychological practice. The topics covered concerned mainly diagnostic process and its effects, among others, developed solutions, dilemmas requiring professional disputes, experiences and problems of psychologists related to diagnosis in various fields of psychology. Another important aspect that was raised is the standardization of the diagnostic process in different areas of psychological practice. Also, experiences were shared in the context of challenges and opportunities for psychological diagnosis in the context of modern global problems, including: problems of the contemporary family (e.g. violence, taking children form their parents due to poverty, labor migration, etc.), competition in sport (diagnosis of athletes, relations in a team, families of children-athletes), mobbing in the work environment, disability, unemployment. The speeches that presented the results of research on the usefulness of different tools for psychological diagnosis were particularly interesting. 